\title{
Critérios de classificação para ocupação informal: Consequências para a caracterização do setor informal e para a análise de bem-estar no Brasil
}

\section{Carlos Henrique Corseuil}

Técnico de Planejamento e Pesquisa - Diretoria de Estudos e Políticas Sociais (Disoc/lpea) Endereço: Av. Presidente Antonio Carlos, 51 - Rio de Janeiro/RJ - Brasil CEP: 20020-010 - E-mail: carlos.corseuil@ipea.gov.br

\author{
Mauricio Cortez Reis \\ Técnico de Planejamento e Pesquisa Diretoria de Estudos e Políticas Sociais (Disoc/lpea) \\ Endereço: Av. Presidente Antonio Carlos, 51 - Rio de Janeiro/RJ - Brasil \\ CEP: 20020-010 - E-mail: mauricio.reis@ipea.gov.br
}

\author{
Alessandra Scalioni Brito \\ Doutoranda - Faculdade de Economia - Universidade Federal Fluminense (UFF) \\ Endereço: Campus do Gragoatá, Bloco F - São Domingos - Niterói/RJ - Brasil \\ CEP: 24210-510 - E-mail: alessandra.scalioni@gmail.com
}

Recebido em 28 de dezembro de 2013. Aceito em 08 de agosto de 2014.

\section{Resumo}

O objetivo deste texto é identificar a sensibilidade da caracterização do trabalhador informal a distintos critérios de classificação entre formal e informal, e mostrar como a relação entre informalidade e medidas de bem-estar dos trabalhadores varia de acordo com o critério de classificação adotado. Como contribuições à literatura, tem-se a análise desagregada para os grupos de empregados e empresários e o uso de um critério recém-disponibilizado para classificar os empresários em formais ou informais, baseado na informação sobre a inclusão no Cadastro Nacional de Pessoa Jurídica (CNPJ). De forma geral, tanto a caracterização do setor informal como a relação entre informalidade e bem-estar são muito parecidas em dois dos três critérios usados; estes são: i) o critério via contribuição à previdência; e ii) o critério baseado no CNPJ para empresários e na carteira de trabalho para empregados.

\section{Palavra-Chave \\ Setor informal.}

\begin{abstract}
In this paper we aim to analyze how sensible is the informal worker profile to distinct classification procedures, as well as to analyze the sensibility of the link between informality and welfare to the same procedures. A disaggregated analysis by employers and employees is one contribution of the paper, which also innovates using information on being included in an official tax payer administrative file (CNPJ) to one of the classification procedures employed to the employers. Two out of three procedures share very similar results in terms of informal worker profile and the link between informality and welfare. These are the procedure based on social security contribution, and the one based on CNPJ for employers and based on legal labor contracts for employees.
\end{abstract}




\section{Keyword}

Informal sector.

\section{JEL Classification}

O17.

\section{Introdução}

Trabalhadores associados ao setor informal tendem a apresentar características distintas daqueles associados ao setor formal. Em particular, pode-se dizer que o setor informal costuma concentrar trabalhadores menos escolarizados, mais jovens, e de cor não branca. Além disso, também se nota que os rendimentos no mercado de trabalho são bem distintos entre os ocupados do setor formal e do informal, o que traz consequências do ponto de vista do bem-estar da população. Como é destacado na literatura, o trabalhador no setor informal tem remuneração mais baixa e, portanto, maior chance de habitar um domicílio pobre, em comparação ao trabalhador no setor formal (Barros, Mello e Pero, 1993). Esses fatos suscitaram um amplo debate na esfera das políticas públicas, visando ampliar o acesso da população em geral a um posto de trabalho formal.

No entanto, a própria definição de ocupação informal vem sendo debatida há várias décadas e ainda carece de um consenso. Consequentemente, há também critérios alternativos para associar os trabalhadores a esses dois setores, uma vez que um dado critério tende a ser balizado por certa definição. Nesse sentido, cabe investigar em que medida os fatos estilizados elencados acima dependem, se não qualitativamente, ao menos quantitativamente do critério de classificação utilizado pelo analista. Este texto procura investigar exatamente essa questão. Existem, portanto, dois objetivos principais: i) o primeiro deles é identificar a sensibilidade da caracterização do trabalhador informal a distintos critérios de classificação; e ii) outro objetivo é mostrar como a relação entre informalidade e medidas de bem-estar dos trabalhadores varia com o critério de classificação.

Este texto traz três contribuições à literatura. A primeira delas é a análise da sensibilidade da relação entre informalidade e bem-estar a distintos critérios de classificação de trabalhadores entre os setores 
formal e informal. Até onde é de conhecimento dos autores, essa relação ainda não havia sido analisada. A segunda contribuição é a análise desagregada para os grupos de empregados e empresários, que de fato mostram realidades bastante distintas. Por fim, o texto também contribui ao incluir um critério inédito para classificar os empresários como formais ou informais, que é baseado na informação sobre inclusão no Cadastro Nacional de Pessoa Jurídica (CNPJ), esta que foi incorporada na Pesquisa Nacional por Amostra de Domicílios (PNAD), do Instituto Brasileiro de Geografia e Estatística (IBGE), a partir de 2009.

A preocupação com a caracterização da informalidade na América Latina, e no Brasil em particular, bem como sua relação com o bem -estar social, foi impulsionada pelo relatório do programa regional de emprego para América Latina e Caribe [PREALC (1978)]. Estudos influentes como os de Souza (1979) e Cacciamali (1983) contribuíram para o aprofundamento dessa análise num primeiro momento e pavimentaram uma rica agenda de pesquisa que permanece ativa.

Os estudos recentes que mais se aproximam deste trabalho são os de Khamis (2012) e Henley, Arabsheibani e Carneiro (2008). Ambos, porém, restringem-se a analisar a sensibilidade da caracterização do informal a diferentes definições de informalidade. Khamis (2012) analisa essa questão para o México e encontra que os critérios legalistas que definem como formalidade "ser coberto pela Seguridade Social" e "ter um contrato (escrito) de trabalho" são significativamente correlacionados e determinados por idade, nível educacional, habilidade e estado civil. Já a medida de informalidade produtivista (trabalhador por conta própria e empregador de pequeno estabelecimento) é influenciada pela idade, escolaridade e estado civil, não sendo a habilidade uma variável significativa neste caso. Henley, Arabsheibani e Carneiro (2008), por seu turno, apresentam uma comparação das características dos trabalhadores formais e informais no Brasil, usando dados da PNAD para o período de 1992 até 2001, e mostram que, dependendo da definição, as características dos indivíduos classificados como informais são muito diferentes. Se, por um lado, a informalidade masculina é maior no critério da carteira de trabalho e menor no baseado no tipo de ocupação e no tamanho do estabelecimento, por outro, a informalidade feminina é maior pelo critério da carteira de trabalho e menor pelo critério de contribuição à previdência social. Nota-se, também, que a informalidade varia 
entre os critérios para cada nível de escolaridade. Como exemplo, a informalidade para analfabetos é menor na definição produtivista se comparada às definições legalistas e, para os trabalhadores com ensino médio ou superior, a informalidade é maior no critério da carteira de trabalho relativamente aos outros dois critérios. Tanto o trabalho de Henley, Arabsheibani e Carneiro (2008) quanto o de Khamis (2012) concluem que diferenças na definição de informalidade podem levar a diagnósticos distintos sobre as características dos setores formal e informal.

O restante do texto está organizado da seguinte forma. A seção 2 apresenta ao leitor o debate conceitual sobre informalidade, bem como seu reflexo em termos de critérios alternativos para classificar os trabalhadores nos setores formal e informal. A seção 3 traz uma descrição da base de dados utilizada, e explicita quais serão os critérios de classificação usados, em particular, expondo o novo critério, comentado acima, com base no CNPJ. Ainda na seção 3, ilustram-se as divergências entre os critérios no que diz respeito à magnitude da informalidade no Brasil. A seção 4 traz a análise sobre a sensibilidade da caracterização do trabalhador informal a distintos critérios de classificação, que vem a ser o primeiro dos objetivos deste trabalho. O conteúdo da seção 5 está atrelado ao segundo objetivo, que é mostrar como a relação entre informalidade e bem-estar dos trabalhadores varia com o critério de classificação. Uma última seção traz um resumo dos principais resultados.

\section{O debate conceitual e suas consequências para a mensuração do fenômeno}

\subsection{Aspectos conceituais}

O debate conceitual sobre informalidade passa a ter expressão a partir do relatório da Organização Internacional do Trabalho (OIT) sobre condições de trabalho no Quênia (OIT, 1972). Nessa publicação, usou-se um conceito de setor informal que se baseava no posicionamento do modo de produção operante na unidade em que o trabalhador exercia seu ofício. Basicamente, o setor informal englobaria “(...) uma série de formas de organização da produção e de possibilidades 
de inserção no mercado de trabalho que não correspondiam à estrutura das firmas e relações trabalhistas predominantes nas economias centrais" (Ramos, 2007). É possível identificar no relatório da OIT algumas características associadas ao setor informal que permitiriam um refinamento do conceito para fins de mensuração e caracterização do fenômeno. Dentre elas, destacam-se: ${ }^{l} i$ ) propriedade familiar do empreendimento; e ii) pequena escala de operações.

Segundo Ramos (2007), outro referencial para conceituar, ainda na década de 1970, o termo informalidade foi o Programa Regional de Emprego para a América Latina e Caribe (PREALC). Cacciamali (2007) destaca como contribuição do PREALC para fins de mensuração e caracterização do fenômeno a introdução da seguinte característica das atividades desse setor:

- não ser organizada juridicamente ou segundo os parâmetros da relação capital-trabalho.

Note-se que essas primeiras contribuições conceituais estão mais associadas à empresa do que ao emprego ou à relação trabalhista. Esse foco na empresa passou a ser explicitado na XV Conferência Internacional de Estatística do Trabalho (CIET), que adotou uma definição estatística para empresas informais. De acordo com Hussmanns (2004) essa definição envolve uma série de condições, dentre as quais destacam-se: ${ }^{2}$ i) empresas não constituídas legalmente como entidades separadas de seus donos; e ii) tamanho abaixo de um certo limite determinado a partir das circunstâncias de cada país e/ou que não sejam registradas perante legislações de abrangência nacionais, tais como de seguridade social ou de pagamento de impostos.

Percebe-se que há uma sobreposição das condições elencadas na XV CIET com aquelas elencadas nos trabalhos pioneiros sobre o tema informalidade, o que comprova uma forte influência dos marcos conceituais estabelecidos nesses trabalhos pioneiros.

1 Segundo Cacciamali (2007), o relatório da OIT elenca também as seguintes características: i) facilidade de entrada; ii) dependência em relação a recursos nativos; iii) intensidade de trabalho e tecnologia adaptada; iv) qualificações adquiridas fora do sistema escolar formal; e v) atuação concentrada em mercados não regulamentados e concorrenciais.

2 O texto de Hussmanns (2004) traz em seu anexo os parágrafos relevantes da resolução da XV CIET que trata dessas condições. 
O foco nos empreendimentos foi objeto de crítica por analistas que almejavam um conceito de informalidade atrelado à relação trabalhista. Diante disso, foi sugerida na XVII CIET a seguinte definição para emprego informal (Hussmanns, 2004):

- empregados em postos informais; ou seja, empregados cuja relação trabalhista não é sujeita a leis trabalhistas, e/ou não credencia o empregado para proteção social e benefícios trabalhistas; e

- trabalhadores por conta própria ou empregadores de empresas informais.

Ou seja, para o empregado a definição é baseada na relação trabalhista; já para o empresário, a definição é baseada nas características da empresa. Essa distinção do conceito de informalidade de acordo com a posição na ocupação dos atores (empresário ou empregado) constitui-se o cerne de nossa análise nesse artigo.

Vale dizer que o reconhecimento das dimensões de informalidade ressaltadas acima - nos empreendimentos e nas relações trabalhistas - são de suma importância para as diretrizes divulgadas em decorrência da XVII CIET relacionadas a conceitos de emprego no setor informal e de emprego informal. O emprego no setor informal compreende a mão de obra ocupada em empreendimentos informais entendidos tal como especificado acima. Já o emprego informal compreende as duas categorias elencadas acima, com a possibilidade de inclusão de parte da mão de obra ocupada em empreendimentos formais. $^{3}$

É inegável a importância da distinção conceitual entre emprego no setor informal e emprego informal, sobretudo para um sistema de contas nacionais que relacione produção e emprego nos setores formal e informal. No entanto, não é essa distinção que será explorada nesse artigo, inclusive por já ser objeto de estudo em outros trabalhos. Ver a esse respeito Hallak Neto et ali (2012) para uma análise nesses moldes para o Brasil, e Krein e Proni (2010) para uma visão crítica da aplicação desse arcabouço conceitual para a realidade brasileira.

3 A distinção pode ser melhor visualizada através da matriz apresentada em OIT (2002) e posteriormente reproduzida em Krein e Proni (2010), página 24 e Hallak Neto et Alli (2012), página 99.

Estud. Econ., São Paulo, vol.45, n.1, p. 5-31, jan.-mar. 2015 


\subsection{Critérios de mensuração}

A seção anterior procura esclarecer a relevância de bases conceituais objetivas para a caracterização da informalidade. Outro aspecto fundamental para essa caracterização se refere ao tipo de informação disponível para o analista responsável pela caracterização do informal. As pesquisas domiciliares e os registros administrativos são as fontes de informações mais comuns. Cada uma delas tem vantagens e limitações para a caracterização da informalidade de acordo com o conceito tomado como base. ${ }^{4}$ A combinação entre bases conceituais e fontes de informação originam diferentes critérios para a caracterização da informalidade. O critério mais tradicional para classificar empresas nos setores formal e informal faz uso de informações sobre o registro da empresa perante o estado. No entanto, nesse tipo de dado não há informação suficiente para quantificar e caracterizar o emprego informal. Logo, é usado, sobretudo, para medir produção do setor informal, e, em alguns poucos casos, também para medir emprego no setor informal, mas não a quantidade de empregos informais. ${ }^{5}$ Em contrapartida, nas pesquisas domiciliares há informação mais detalhada sobre a relação trabalhista. Contudo, não é comum ter informação sobre a constituição legal da empresa, por isso os trabalhos que se debruçam nesse tipo de base de dados tendem a gerar números sobre o montante de emprego informal, mas não sobre empregos no setor informal.

Os trabalhos baseados em pesquisas domiciliares lançam mão de diferentes critérios. Um primeiro critério é fundamentado no tamanho dos estabelecimentos para empregados e empregadores e na ocupação para os trabalhadores por conta própria. Segundo esse critério, são considerados formais aqueles em estabelecimentos com mais de cinco funcionários, enquanto os trabalhadores por conta própria são considerados formais se a ocupação é considerada criativa e técnica ou administrativa ou referente a atividades profissionais (Henley, Arabsheibani e Carneiro, 2008). A questão do tamanho é definida pelas condições estabelecidas tanto no relatório original da OIT como na XV CIET. A questão do trabalhador por conta pró-

4 Ver OIT (2013) para uma discussão mais aprofundada sobre potencialidades e problemas advindos de cada fonte de dados. Rocha (1989) já vislumbrava essa preocupação para o caso brasileiro.

5 Para uso desse tipo de informação restrito à produção, ver Schneider e Enste (2000); e para apresentação de números referentes a produção e emprego no setor informal, ver Schneider (2011). 
pria funda-se na condição sobre regulamentação do negócio presente na contribuição do PREALC e também da XV CIET. Nesse caso, supõe-se que o profissional liberal deva ter seu empreendimento regulamentado.

Outro critério utilizado na literatura, que tem como vantagem ser baseado em informação frequentemente encontrada em pesquisas domiciliares de uso público, associa trabalhadores cobertos por sistemas de previdência social ao setor formal, independentemente da condição de empregado ou empresário. Para que esse método encontre respaldo nos conceitos discutidos no âmbito da XVII CIET, supõe-se que o empresário que não contribui para a previdência tende a burlar também o fisco e as regulações relevantes para a empresa. De forma análoga, acredita-se que o empregado que não conta com cobertura previdenciária também tem uma relação trabalhista à margem da legislação relevante.

No caso do Brasil, há como checar se a relação trabalhista do empregado está à margem da legislação relevante, visto que a informação sobre a posse de carteira assinada encontra-se disponível nas principais pesquisas domiciliares conduzidas em larga escala e com dados acessíveis ao público. Logo, usa-se no Brasil uma alternativa para esse último critério, mas que só se aplica stricto sensu aos trabalhadores ocupados como empregados. Trata-se de associar o setor formal à posse de carteira de trabalho assinada, uma vez que esse documento garante uma série de benefícios para o trabalhador.

Os cientistas sociais brasileiros, em particular os economistas, logo adotaram esse último critério como o padrão. Mas, nesse critério, não é claro como devem ser classificados os indivíduos que trabalham como trabalhadores por conta própria ou empregadores. Convencionou-se incluir todos os trabalhadores por conta própria no setor informal e todos os empregadores no setor formal. ${ }^{6}$

$\overline{6}$ Ver Henley, Arabsheibani e Carneiro (2008).

Estud. Econ., São Paulo, vol.45, n.1, p. 5-31, jan.-mar. 2015 


\section{Aspectos metodológicos}

Três diferentes critérios serão usados para classificar empregados e empresários (empregadores e trabalhadores autônomos) de forma separada nos setores formal e informal neste trabalho. O primeiro critério considera formal o empregado com carteira assinada, assim como o empresário que possui registro no CNPJ. O segundo critério usado para definir formalidade é baseado na contribuição para a previdência social tanto para o empregado como para o empresário. O terceiro critério classifica como formais o empregado e o empregador que estejam em empresas com mais de cinco funcionários ${ }^{7}$ e o trabalhador por conta própria ocupado como "profissional das ciências e das artes" ou "dirigente".

Os dois últimos critérios já foram utilizados anteriormente, tal como reportado na seção anterior. O primeiro critério traz uma novidade, satisfazendo duas bases conceituais distintas. O primeiro conceito que pode ser usado para fundamentar tal critério é aquele que associa o setor formal a benefícios providos pelo Estado. Pelo lado do empregado, é fato que a carteira de trabalho lhe assegura uma série de benefícios que, se não diretamente providos pelo Estado, são, em tese, garantidos por ele, tais como seguro-desemprego, férias e repousos remunerados, Fundo de Garantia do Tempo de Serviço (FGTS), multa rescisória e outros. Pelo lado do empresário há também uma série de vantagens para aqueles registrados perante o Estado, tais como acesso privilegiado a crédito, possibilidade de ter o governo como comprador da sua produção, acesso facilitado à capacitação para o empresário em áreas tais como gerenciamento e comercialização. O segundo conceito é aquele que associa o setor formal a entes visíveis para o Estado e, portanto, sujeito à cobrança de tributos sobre a remuneração da sua atividade produtiva. De fato, o empregado com carteira tem sua contribuição para a previdência descontada em folha e é sujeito à fiscalização quanto ao pagamento de Imposto de Renda (IR). O elo do empresário com o Estado pelo CNPJ é ainda mais imediato.

Com base nesses três critérios, será feita uma análise empírica que utiliza os microdados da PNAD para os anos de 2009 e 2011, pois

7 Como o funcionário público e o militar não respondem à questão sobre tamanho do estabelecimento, consideram-se todos eles como formais neste critério, uma vez que trabalham em estabelecimentos com muitos funcionários. 
apenas para esse período é possível obter informações sobre a inscrição do indivíduo no CNPJ. Fazem parte da amostra todos os indivíduos com idade superior a 10 anos, ocupados na semana de referência da PNAD, exceto os empregados rurais. Isto é feito para possibilitar a comparação entre os critérios de informalidade, já que um desses critérios é baseado no tamanho do estabelecimento em que o empregado trabalha, e na PNAD não existe uma pergunta específica sobre tamanho do estabelecimento para esse grupo de trabalhadores rurais.

A Tabela 1 mostra a proporção de trabalhadores classificados como informais segundo cada um dos três critérios utilizados. Os resultados são apresentados separadamente para empregados e empresários (empregadores e trabalhadores por conta própria), assim como para cada um dos anos. Para os empregados, 32\% são considerados informais de acordo com o critério baseado na carteira de trabalho, enquanto pela contribuição para a previdência os informais representariam 28\% dos empregados em 2009. Essa diferença pode ser explicada pelo fato de uma parcela dos trabalhadores sem carteira contribuir para a previdência, enquanto a totalidade dos empregados com carteira contribui. O grau de informalidade entre os empregados registra o maior valor, com 36\% em 2009, quando medido pelo critério baseado no tamanho da empresa.

Tabela 1 - Grau de informalidade dos ocupados (em \%) - 2009 e 2011

\begin{tabular}{|c|c|c|c|}
\hline & \multicolumn{3}{|c|}{ Critério } \\
\hline & $\begin{array}{l}\text { carteira de } \\
\text { trabalho/CNPJ }\end{array}$ & previdência & tamanho/ocupação \\
\hline \multicolumn{4}{|c|}{2009} \\
\hline Empregados & 32,2 & 27,6 & 36,4 \\
\hline Não empregados* & 76,5 & 76,4 & 91,2 \\
\hline \multicolumn{4}{|l|}{2011} \\
\hline Empregados & 28,3 & 23,5 & 34,8 \\
\hline Não empregados & 76,1 & 72,0 & 89,8 \\
\hline
\end{tabular}

* Empregador e trabalhador por conta própria.

Fonte: PNAD 2009 e 2011.

Note-se que a participação dos informais é muito maior entre os empresários do que entre os empregados nos três critérios. Pelos dois primeiros critérios, baseados no CNPJ e na contribuição para a previdência, mais de três quartos dos empresários são classificados como informais em 2009 (em torno de 76\%). 
A informalidade para os empresários passa de $90 \%$ quando medida pelo terceiro critério, que usa tanto o tamanho da empresa como características da ocupação.

\section{A sensibilidade da caracterização do trabalhador informal}

Esta seção apresenta algumas estatísticas descritivas comparando uma série de características dos trabalhadores formais e informais de acordo com cada um dos critérios definidos na seção anterior. A análise é feita separadamente para empregados e empresários.

Uma estatística própria para sumarizar o quão semelhantes são os conjuntos de indivíduos definidos por dois critérios alternativos é o grau de correlação entre esses conjuntos. A Tabela 2 traz essa informação para cada par de comparações possíveis, tanto para empregados como para empregadores.

Tabela 2 - Correlações entre os critérios de informalidade - 2009 e 2011

Empregados

\begin{tabular}{|c|c|c|c|}
\hline & carteira & previdência & tamanho \\
\hline carteira & 1 & 0,8651 & 0,5198 \\
\hline previdência & 0,8729 & 1 & 0,4314 \\
\hline tamanho & 0,5299 & 0,447 & 1 \\
\hline
\end{tabular}

Empresários

\begin{tabular}{c|c|r|r|r|}
\multicolumn{5}{c|}{2011} \\
\hline & CNPJ & previdência & tamanho \\
\cline { 2 - 5 } & CNPJ & 1 & 0,5068 & 0,2798 \\
\hline previdência & 0,44 & 1 & 0,2167 \\
\hline tamanho & 0,287 & 0,2325 & 1 \\
\hline
\end{tabular}

Fonte: PNAD 2009 e 2011.

Concernente aos empregados, a correlação entre os critérios 1 e 2 é bastante elevada, 0,87 nos dois períodos. Já as correlações envolvendo o critério 3 são mais baixas, registrando em 2009 os valores de 0,45 entre os critérios 2 e 3 e de 0,53 entre 1 e 3 . Já entre os empresários, as magnitudes das correlações são bem menores, quase sempre abaixo de 0,5 . Por exemplo, as correlações entre os critérios 1 e 3 e entre 2 e 3 são 0,29 e 0,23, respectivamente, em 2009. Os valores para 2011 são mais baixos ainda. Mesmo na comparação dos conjuntos de trabalhadores formados pelos critérios 1 e 2 , que registram taxas de informalidade quase idênticas, a correlação varia entre 0,44 e 0,51 nos dois períodos. É interessante notar, entretanto, que 
os resultados são similares aos registrados para os empregados no aspecto qualitativo, ou seja, as correlações mais fortes aparecem entre os critérios 1 e 2, e as mais baixas quando o critério 3 é utilizado.

\subsection{Análise univariada para empregados}

Com o intuito de ilustrar onde estão as maiores diferenças entre os conjuntos de trabalhadores formados por critérios distintos, serão apresentadas agora informações referentes a uma série de características desses trabalhadores. Todos os resultados mostrados no restante do artigo são referentes aos dados agregados para os dois períodos (2009 e 2011).

Começou-se pelas características tradicionalmente associadas a atributos produtivos; são elas: i) escolaridade, idade (indicando experiência no mercado de trabalho); e ii) experiência no emprego. O valor médio de cada uma dessas variáveis em cada combinação de setor (formal ou informal) e critério de classificação está ilustrado na Tabela 3.

É nítido que o setor formal quase não registra variação nas médias de anos de estudo e de tempo de emprego entre os diferentes critérios de classificação. Por exemplo, a média de anos de estudo para empregados formais é igual a 10,1 anos em todos os critérios e o tempo de emprego varia de 5,8 a 6,2 anos dependendo do critério. Em relação à idade, a discrepância maior ocorre entre os critérios 2 e 3, mas é inferior a um ano. O diagnóstico para o setor informal não muda muito com relação às duas primeiras variáveis, visto que as alterações nos valores também são bem modestas, ainda que maiores do que aquelas apresentadas para o setor formal. Também a título de exemplo, a média de anos de estudo dos empregados informais varia de 7,5 a 8,2 anos, dependendo do critério de formalidade utilizado, enquanto a discrepância entre as idades médias chega a 2,5 anos.

Tabela 3 - Características médias dos Empregados formais e informais - 2009. 2011

\begin{tabular}{lcccccc}
\hline Médias & carteira & $\begin{array}{c}\text { Formal } \\
\text { previdência }\end{array}$ & tamanho & carteira & $\begin{array}{c}\text { Informal } \\
\text { previdência }\end{array}$ & tamanho \\
\hline Anos de estudo & 10,1 & 10,1 & 10,1 & 7,9 & 7,5 & 8,2 \\
Idade & 35,8 & 36 & 35,1 & 33,5 & 32,7 & 35,2 \\
Tempo de emprego & 6,2 & 6,2 & 5,8 & 3,9 & 3,6 & 5 \\
\hline
\end{tabular}

Fonte: PNAD 2009 e 2011. 
A Tabela 4 apresenta as distribuições, definidas de acordo com cada um dos critérios utilizados neste estudo, de outras características para empregados tanto no setor formal como no informal; são elas: cor; gênero; região geográfica; e setor de atividade. As distribuições dos empregados formais e informais por cor ou raça são bem semelhantes seja qual for o critério utilizado. A maior diferença é registrada para a comparação entre as distribuições de empregados informais envolvendo o critério 3. Por exemplo, o percentual de pretos e pardos entre os informais é cerca de $58 \%$ quando se usa o critério 2 e de $54 \%$ com o critério 3 . Essa diferença é compensada no percentual de brancos, que vem a ser 4 pontos de porcentagem maior no critério 3 em relação ao 2 .

Os resultados por gênero confirmam a semelhança entre os conjuntos definidos pelos dois primeiros critérios, em que a proporção de homens fica em torno de $45 \%$ no setor informal e $55 \%$ no formal. Os conjuntos formados pelo critério 3, embora difiram, não chegam a destoar dos demais quando se analisa a distribuição por gênero. De acordo com o critério 3 , tem-se $61 \%$ de homens no setor formal, e $39 \%$ no informal.

Tabela 4 - Características individuais e do emprego dos Empregados formais e informais - 2009-2011

\begin{tabular}{|c|c|c|c|c|c|c|}
\hline & \multicolumn{2}{|c|}{ Formal } & \multirow[b]{2}{*}{ tamanho } & \multicolumn{3}{|c|}{ Informal } \\
\hline & carteira & previdência & & carteira & previdência & tamanho \\
\hline \multicolumn{7}{|c|}{ Cor } \\
\hline Indígena & $0,2 \%$ & $0,3 \%$ & $0,3 \%$ & $0,3 \%$ & $0,3 \%$ & $0,3 \%$ \\
\hline Branco & $54,2 \%$ & $53,8 \%$ & $53,6 \%$ & $42,6 \%$ & $41,4 \%$ & $45,3 \%$ \\
\hline Preto & $8,5 \%$ & $8,5 \%$ & $8,4 \%$ & $9,4 \%$ & $9,6 \%$ & $9,4 \%$ \\
\hline Amarelo & $0,5 \%$ & $0,5 \%$ & $0,5 \%$ & $0,5 \%$ & $0,4 \%$ & $0,4 \%$ \\
\hline Pardo & $36,6 \%$ & $36,9 \%$ & $37,2 \%$ & $47,2 \%$ & $48,2 \%$ & $44,6 \%$ \\
\hline \multicolumn{7}{|c|}{ Gênero } \\
\hline Homem & $56,1 \%$ & $55,0 \%$ & $60,1 \%$ & $44,2 \%$ & $45,3 \%$ & $38,8 \%$ \\
\hline Mulher & $43,9 \%$ & $45,0 \%$ & $39,9 \%$ & $55,8 \%$ & $54,7 \%$ & $61,2 \%$ \\
\hline \multicolumn{7}{|c|}{ Regiões } \\
\hline Centro-oeste & $7,8 \%$ & $7,9 \%$ & $7,7 \%$ & $8,4 \%$ & $8,3 \%$ & $8,6 \%$ \\
\hline Nordeste & $17,4 \%$ & $18,0 \%$ & $18,2 \%$ & $29,6 \%$ & $29,8 \%$ & $26,2 \%$ \\
\hline Norte & $5,5 \%$ & $5,8 \%$ & $5,9 \%$ & $9,4 \%$ & $9,2 \%$ & $8,1 \%$ \\
\hline Sudeste & $51,8 \%$ & $51,0 \%$ & $51,1 \%$ & $39,7 \%$ & $39,8 \%$ & $42,7 \%$ \\
\hline Sul & $17,5 \%$ & $17,2 \%$ & $17,1 \%$ & $12,9 \%$ & $12,8 \%$ & $14,4 \%$ \\
\hline \multicolumn{7}{|c|}{ Setor de atividade } \\
\hline Adm. Pública & $9,4 \%$ & $10,1 \%$ & $8,3 \%$ & $5,7 \%$ & $3,1 \%$ & $8,4 \%$ \\
\hline Comércio & $18,6 \%$ & $18,0 \%$ & $19,2 \%$ & $17,4 \%$ & $18,9 \%$ & $16,5 \%$ \\
\hline Construção civil & $5,4 \%$ & $5,3 \%$ & $6,6 \%$ & $9,5 \%$ & $10,7 \%$ & $6,7 \%$ \\
\hline Indústria & $20,9 \%$ & $20,0 \%$ & $23,9 \%$ & $9,9 \%$ & $10,6 \%$ & $6,1 \%$ \\
\hline Serviços para empresas & $16,3 \%$ & $15,8 \%$ & $16,8 \%$ & $11,7 \%$ & $12,3 \%$ & $11,5 \%$ \\
\hline Serviços para pessoas & $22,9 \%$ & $24,5 \%$ & $18,1 \%$ & $42,1 \%$ & $40,8 \%$ & $47,8 \%$ \\
\hline Transporte & $6,6 \%$ & $6,4 \%$ & $7,1 \%$ & $3,6 \%$ & $3,6 \%$ & $3,0 \%$ \\
\hline
\end{tabular}

Fonte: PNAD 2009 e 2011. 
A similaridade entre os dois primeiros critérios e uma diferença não tão marcante na distribuição resultante do terceiro critério também são a tônica na comparação das distribuições dos empregados informais por região geográfica. A Tabela 3 mostra que os empregados informais são distribuídos entre as grandes regiões de forma muito similar quando se usa um dos dois primeiros critérios. Já quando o critério 3 é usado, há uma concentração menor de trabalhadores informais no Nordeste, e maior nas regiões Sul e Sudeste. Já as distribuições dos empresários formais por região geográfica são todas bem similares.

A comparação das distribuições dos empregados conforme o setor de atividade também mostra maiores diferenças quando se usa o critério 3. Os percentuais de empregados (in)formais na indústria e na construção civil são (menores) maiores no critério 3 do que nos demais. Essas diferenças são compensadas por (maiores) menores percentuais na administração pública e no segmento de serviços voltado a pessoas.

Em suma, a análise para o grupo de empregados revela que a caracterização dos setores formal e informal é muito peculiar quando se usa o critério de tamanho da empresa. Em geral, essa caracterização é mais homogênea se se restringir aos critérios baseados na carteira de trabalho ou na contribuição à previdência. Outro resultado frequente nessa análise foi a maior sensibilidade do setor informal, onde a caracterização dos trabalhadores varia relativamente mais ao critério de classificação do que no setor formal.

\subsection{Análise univariada para empresários}

A Tabela 5 apresenta as médias das características tradicionalmente associadas a atributos produtivos para empresários formais e informais, conforme os três critérios de informalidade: $i$ i) inscrição no CNPJ; ii) contribuição à previdência; e iii) tamanho do estabelecimento (empregador) ou ocupação (trabalhador por conta própria). 
Tabela 5 - Características médias dos Empresários formais e informais - 2009. 2011

\begin{tabular}{lcccccc}
\hline & \multicolumn{3}{c}{ Formal } & & \multicolumn{3}{c}{ Informal } \\
Médias & CNPJ & previdência & tamanho & CNPJ & previdência & tamanho \\
\hline Anos de estudo & 10,5 & 9,8 & 12,4 & 6,3 & 6,4 & 6,8 \\
Idade & 43,8 & 44,6 & 43,8 & 43,8 & 43,5 & 43,8 \\
Tempo de emprego & 11 & 12,8 & 11,7 & 12,3 & 11,7 & 12 \\
\hline
\end{tabular}

Fonte: PNAD 2009 e 2011.

Para empresários informais, a média das três variáveis diverge pouco de um critério para outro. A maior média de anos de estudo ocorre no terceiro critério $(6,8$ anos), bem como a maior média de idade (43,8 anos), e o valor máximo do tempo de emprego ocorre no critério de inscrição no CNPJ (12,3 anos). Em relação aos empresários formais, as diferenças entre os critérios também não são muito grandes, apesar de serem maiores que no caso dos informais. A média de anos de estudo é a de maior discrepância entre os critérios $(2,6)$, variando de 9,8 a 12,4 anos. Já a média de idade é a que apresenta menor diferença entre os critérios $(0,8)$, enquanto o tempo de emprego varia de 11 a 12,8 anos.

A Tabela 6 mostra as características individuais e laborais dos empresários (trabalhadores por conta própria e empregadores) segundo os três critérios de informalidade. Nela, pode-se ver que a distribuição dos empresários, tanto formais quanto informais, não varia muito entre os critérios de CNPJ e previdência, com uma diferença um pouco maior no critério de tamanho do estabelecimento ou ocupação dos trabalhadores por conta própria (critério 3). Enquanto os empresários formais são majoritariamente brancos (de 69,8\% a 73,9\%, dependendo do critério utilizado), os empresários informais se dividem em brancos e pardos, sendo a maioria de cor branca apenas no terceiro critério. 
Tabela 6 - Características individuais e do emprego dos Empresários formais e informais - 2009-2011

\begin{tabular}{|c|c|c|c|c|c|c|}
\hline & \multicolumn{3}{|c|}{ Formal } & \multicolumn{3}{|c|}{ Informal } \\
\hline & CNPJ & previdência & tamanho & CNPJ & previdência & tamanho \\
\hline \multicolumn{7}{|c|}{ Cor } \\
\hline Indígena & $0,2 \%$ & $0,2 \%$ & $0,3 \%$ & $0,4 \%$ & $0,4 \%$ & $0,4 \%$ \\
\hline Branco & $70,6 \%$ & $69,8 \%$ & $73,9 \%$ & $44,4 \%$ & $43,9 \%$ & $48,2 \%$ \\
\hline Preto & $3,7 \%$ & $4,3 \%$ & $3,4 \%$ & $8,2 \%$ & $8,1 \%$ & $7,5 \%$ \\
\hline Amarelo & $1,4 \%$ & $1,2 \%$ & $1,4 \%$ & $0,4 \%$ & $0,5 \%$ & $0,6 \%$ \\
\hline Pardo & $24,1 \%$ & $24,5 \%$ & $21,0 \%$ & $46,6 \%$ & $47,0 \%$ & $43,4 \%$ \\
\hline \multicolumn{7}{|c|}{ Gênero } \\
\hline Homem & $68,4 \%$ & $70,1 \%$ & $59,6 \%$ & $68,5 \%$ & $68,0 \%$ & $69,4 \%$ \\
\hline Mulher & $31,6 \%$ & $29,9 \%$ & $40,4 \%$ & $31,5 \%$ & $32,0 \%$ & $30,6 \%$ \\
\hline \multicolumn{7}{|c|}{ Regiões } \\
\hline Centro-oeste & $8,8 \%$ & $7,4 \%$ & $7,6 \%$ & $7,2 \%$ & $7,6 \%$ & $7,5 \%$ \\
\hline Nordeste & $14,3 \%$ & $13,2 \%$ & $15,6 \%$ & $33,7 \%$ & $34,7 \%$ & $30,5 \%$ \\
\hline Norte & $4,6 \%$ & $3,3 \%$ & $4,5 \%$ & $10,6 \%$ & $11,3 \%$ & $9,7 \%$ \\
\hline Sudeste & $48,6 \%$ & $51,0 \%$ & $52,1 \%$ & $35,2 \%$ & $34,0 \%$ & $36,9 \%$ \\
\hline Sul & $23,6 \%$ & $25,1 \%$ & $20,2 \%$ & $13,3 \%$ & $12,5 \%$ & $15,3 \%$ \\
\hline \multicolumn{7}{|c|}{ Setor de atividade } \\
\hline Agricultura & $4,8 \%$ & $10,2 \%$ & $1,6 \%$ & $24,9 \%$ & $23,5 \%$ & $22,0 \%$ \\
\hline Comércio & $39,4 \%$ & $30,8 \%$ & $13,6 \%$ & $20,5 \%$ & $23,0 \%$ & $26,2 \%$ \\
\hline Construção civil & $4,3 \%$ & $9,1 \%$ & $3,1 \%$ & $17,7 \%$ & $16,4 \%$ & $15,7 \%$ \\
\hline Indústria & $11,4 \%$ & $10,9 \%$ & $21,3 \%$ & $11,5 \%$ & $11,7 \%$ & $10,5 \%$ \\
\hline Serviços para empresas & $23,4 \%$ & $19,0 \%$ & $34,2 \%$ & $9,2 \%$ & $10,3 \%$ & $10,3 \%$ \\
\hline Serviços para pessoas & $11,5 \%$ & $12,2 \%$ & $24,2 \%$ & $9,7 \%$ & $9,4 \%$ & $8,6 \%$ \\
\hline Transporte & $5,2 \%$ & $7,9 \%$ & $1,9 \%$ & $6,5 \%$ & $5,6 \%$ & $6,7 \%$ \\
\hline
\end{tabular}

Fonte: PNAD 2009 e 2011.

A distribuição por gênero dos empresários informais é relativamente próxima entre os três critérios (proporção de homens de $68 \%$ a $69,4 \%$ ), o que só ocorre para os empresários formais entre os dois primeiros critérios, sendo a proporção máxima de homens encontrada no critério de contribuição à previdência $(70,1 \%)$ e a mínima, no critério de tamanho do estabelecimento $(59,6 \%)$. Em relação às regiões geográficas, as participações do Sudeste e do Nordeste são muito próximas nos critérios 1 e 2 , enquanto o critério 3 mostra uma participação do Sudeste maior em 6 pontos percentuais (p.p.). Já para os empresários formais, a região Sudeste é a de maior peso, seguida pela região Sul, independentemente do critério de informalidade utilizado. 
A distribuição dos empresários informais, conforme o setor de atividade, diverge pouco entre os três critérios, exceto para a participação do comércio, que varia entre $20 \%$ e $26 \%$. Para os empresários formais, contudo, as diferenças entre os critérios se tornam mais significativas, sobretudo em relação ao terceiro critério. Enquanto o setor com maior participação é o comércio nos critérios de CNPJ $(39,4 \%)$ e previdência $(30,8 \%)$, no critério de tamanho/ocupação destaca-se o setor de serviços para empresas $(34,2 \%)$. Para exemplificar a discrepância do critério de tamanho/ocupação relativamente aos demais, merece destaque o fato de os pesos dos setores industrial e de serviços para pessoas serem quase o dobro no terceiro critério em relação aos dois primeiros.

Portanto, da análise das características individuais e laborais dos empresários conclui-se que, quando existem, as maiores diferenças entre os critérios de informalidade ocorrem quando é utilizada a classificação baseada no tamanho do estabelecimento ou na ocupação do trabalhador por conta própria (critério 3).

\subsection{Análise multivariada}

Nesta subseção são mostrados os resultados estimados para a probabilidade de um indivíduo estar ocupado em um emprego informal, que pode ser definido de acordo com cada um dos diferentes critérios descritos anteriormente. A probabilidade de ocupar um emprego informal é representada como uma função de características individuais, do domicílio e do setor de atividade, conforme a Equação (1):

$$
P(y=1 \mid X)=F\left(\beta_{0}+\beta_{1} X\right)
$$

em que y é uma variável binária indicando que o indivíduo é informal e $\mathrm{F}$ ( ) representa a função distribuição normal padrão acumulada. Como controles, são incluídas as seguintes variáveis: idade; idade ${ }^{2}$; anos de estudo; número de idosos (65 anos ou mais) no domicílio; e número de crianças (menores de 10 anos); além de dummies para setor, região, negro, mulher, ano (2011). As regressões são estimadas separadamente para empregados e empresários e para cada um dos critérios de informalidade. 
A Tabela 7 mostra os efeitos marginais estimados e os respectivos erros-padrão nas seis situações consideradas. Nas três primeiras colunas, tem-se os resultados referentes a cada um dos três critérios de classificação para o grupo de empregados, enquanto nas três últimas colunas, os resultados para o grupo de empresários.

Tabela 7

\begin{tabular}{|c|c|c|c|c|c|c|c|}
\hline & & Empregados & & & & Empresários & \\
\hline Variáveis & carteira & previdência & tamanho & Variáveis & CNPJ & previdência & tamanho \\
\hline Administracãn núhlica & $0.0564^{* \star *}$ & $-0.0597^{* * *}$ & $0.243^{* * *}$ & Aaricultura & $0.101^{* * *}$ & $0.0979^{\star \star *}$ & $0.0164^{* * *}$ \\
\hline 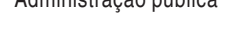 & $(0.00684)$ & $(0.00547)$ & $(0.00727)$ & Agricurtura & $(0.00554)$ & $(0.00592)$ & $(0.00310)$ \\
\hline Serviços para & $0.232^{* \star *}$ & $0.178^{\star * *}$ & $0.374^{\star \star *}$ & Serviços para & $-0.0439^{* * *}$ & $0.0370^{\star * *}$ & $-0.150^{\text {*** }}$ \\
\hline pessoas & $(0.00607)$ & $(0.00587)$ & $(0.00598)$ & pessoas & $(0.00863)$ & $(0.00740)$ & $(0.0113)$ \\
\hline Serviços para & $0.0302^{* * *}$ & $0.0358^{* * *}$ & $0.0832^{* * *}$ & Serviços para & $-0.162^{* * *}$ & 0.0119 & $-0.142^{\star * *}$ \\
\hline empresas & $(0.00605)$ & $(0.00572)$ & $(0.00664)$ & empresas & $(0.00960)$ & $(0.00727)$ & $(0.0102)$ \\
\hline & $-0.0640^{\star * *}$ & $-0.0474^{* * *}$ & $-0.134^{\star \star *}$ & & $-0.0703^{* * *}$ & $0.0535^{* * *}$ & $-0.188^{* * *}$ \\
\hline Industria & $(0.00529)$ & $(0.00485)$ & $(0.00553)$ & Industria & $(0.00877)$ & $(0.00684)$ & $(0.0122)$ \\
\hline Construcão & $0.171^{\star \star \star}$ & $0.170^{\star * *}$ & $0.112^{* \star \star}$ & Construcão & $0.115^{\star \star \star}$ & $0.125^{\star * *}$ & -0.00344 \\
\hline Construçao & $(0.00745)$ & $(0.00741)$ & $(0.00748)$ & Construçao & $(0.00489)$ & $(0.00526)$ & $(0.00402)$ \\
\hline Comércio & $0.0438^{* * *}$ & $0.0493^{* * *}$ & $0.104^{* * *}$ & Comércio & $-0.187^{\star * *}$ & -0.00322 & $-0.0213^{* * *}$ \\
\hline evinticio & $(0.00589)$ & $(0.00558)$ & $(0.00643)$ & comercio & $(0.00830)$ & $(0.00682)$ & $(0.00422)$ \\
\hline & $0.103^{\star \star}$ & 0.0680 & $0.119^{\star \star \star}$ & & $0.118^{\star \star \star}$ & $0.177^{\star * *}$ & $0.0304^{\star * *}$ \\
\hline AtIV. mal definidas & $(0.0468)$ & $(0.0439)$ & $(0.0445)$ & Ativ. mal definidas & $(0.0144)$ & $(0.00905)$ & $(0.00258)$ \\
\hline $\mathrm{CO}$ & $0.0536^{* * *}$ & $0.0405^{* * *}$ & $0.0434^{* * *}$ & $\mathrm{CO}$ & $-0.0215^{\star * *}$ & $0.0433^{* * *}$ & -0.000632 \\
\hline 0 & $(0.00367)$ & $(0.00342)$ & $(0.00377)$ & 0 & $(0.00494)$ & $(0.00450)$ & $(0.00185)$ \\
\hline & $-0.0112^{* * *}$ & $-0.0136^{\star \star *}$ & $0.0112^{* * *}$ & & $-0.0666^{* * *}$ & $-0.0657^{* * *}$ & $-0.00615^{\star * *}$ \\
\hline Sul & $(0.00321)$ & $(0.00295)$ & $(0.00346)$ & Sul & $(0.00469)$ & $(0.00486)$ & $(0.00171)$ \\
\hline Norte & $0.151^{\star \star \star}$ & $0.112^{* \star *}$ & $0.0813^{* * *}$ & Norte & $0.0735^{* * *}$ & $0.150^{\star * *}$ & $0.00516^{* * *}$ \\
\hline Norte & $(0.00397)$ & $(0.00378)$ & $(0.00402)$ & inorte & $(0.00375)$ & $(0.00330)$ & $(0.00183)$ \\
\hline $\mathrm{NF}$ & $0.138^{\star * \star}$ & $0.110^{* * *}$ & $0.0806^{* * *}$ & $N F$ & $0.0860^{* * *}$ & $0.134^{* * *}$ & 0.00218 \\
\hline IVE & $(0.00303)$ & $(0.00285)$ & $(0.00314)$ & TNE & $(0.00350)$ & $(0.00358)$ & $(0.00151)$ \\
\hline Ano & $-0.0316^{* * *}$ & $-0.0328^{* * *}$ & $-0.00460^{* *}$ & Ano $>2+2>$ & $-6.02 e-05$ & $-0.0429^{* * *}$ & $-0.00910^{* * *}$ \\
\hline Allo & $(0.00218)$ & $(0.00201)$ & $(0.00233)$ & Anlo & $(0.00295)$ & $(0.00320)$ & $(0.00117)$ \\
\hline & $-0.0283^{* \star \star}$ & $-0.0291^{* * *}$ & $-0.0321^{* * *}$ & & $-0.0239^{* * *}$ & $-0.0227^{\star * *}$ & $-0.00952^{* * *}$ \\
\hline Anos de estudo & $(0.000293)$ & $(0.000268)$ & $(0.000310)$ & Anos de estudo & $(0.000387)$ & $(0.000417)$ & $(0.000208)$ \\
\hline & $0.00637^{* * *}$ & $0.00760^{* * *}$ & 0.00254 & Nearn & $0.0732^{* * *}$ & $0.0708^{* * *}$ & $0.0177^{\star \star *}$ \\
\hline Negro & $(0.00237)$ & $(0.00218)$ & $(0.00253)$ & Negro & $(0.00324)$ & $(0.00349)$ & $(0.00134)$ \\
\hline Mulher & $0.0767^{\star * *}$ & $0.0659^{* * *}$ & $0.117^{\star * *}$ & Mulher & $0.0883^{* * *}$ & $0.0797^{* * *}$ & $0.0127^{\star * *}$ \\
\hline Muluner & $(0.00254)$ & $(0.00235)$ & $(0.00265)$ & Munner & $(0.00303)$ & $(0.00353)$ & $(0.00117)$ \\
\hline $\mathrm{dade}^{2}$ & $0.000435^{* \star *}$ & ${ }^{*} 0.000399^{* * *}$ & $0.000205^{* * \star}$ & $\mathrm{dade}^{2}$ & $6.21 \mathrm{e}-05^{\star \star *}$ & $0.000277^{\star * *}$ & $-2.64 e-07$ \\
\hline Idaade ${ }^{2}$ & $(1.05 e-05)$ & $(9.52 \mathrm{e}-06)$ & $(7.32 \mathrm{e}-06)$ & Idaade ${ }^{2}$ & $(8.11 \mathrm{e}-06)$ & $(1.25 \mathrm{e}-05)$ & $(2.93 e-06)$ \\
\hline & $-0.0392^{* \star *}$ & $-0.0369^{* \star *}$ & $-0.0195^{\star * \star}$ & & $-0.00778^{* * *}$ & $-0.0282^{* * *}$ & $-0.000686^{* *}$ \\
\hline Idade & $(0.000778)$ & $(0.000701)$ & $(0.000558)$ & Idade & $(0.000709)$ & $(0.00108)$ & $(0.000259)$ \\
\hline Númern de idosos & $0.0117^{* * *}$ & $0.0130^{* * *}$ & $0.0162^{* * *}$ & lúmernde idosos & $0.0204^{* * *}$ & $0.0310^{* * *}$ & $0.00213^{*}$ \\
\hline 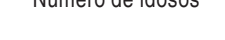 & $(0.00278)$ & $(0.00257)$ & $(0.00297)$ & Numero de laosos & $(0.00355)$ & $(0.00411)$ & $(0.00128)$ \\
\hline Número de criancas & $0.0105^{* * *}$ & $0.00885^{* * *}$ & -0.00110 & & 0.000780 & $0.0120^{* * *}$ & $8.94 \mathrm{e}-05$ \\
\hline Numero de crlanças & $(0.00143)$ & $(0.00130)$ & $(0.00151)$ & Numero de crıanças & $(0.00198)$ & $(0.00221)$ & $(0.000834)$ \\
\hline Observações & 230491 & 230491 & 230491 & Observações & 90439 & 90439 & 90439 \\
\hline Pseudo $\mathrm{R}^{2}$ & 0.1551 & 0.1768 & 0.1667 & Pseudo $\mathrm{R}^{2}$ & 0.2448 & 0.1885 & 0.3003 \\
\hline
\end{tabular}

Fonte: PNAD 2009 e 2011.

Estud. Econ., São Paulo, vol.45, n.1, p. 5-31, jan.-mar. 2015 
Os efeitos estimados para escolaridade, idade, gênero, cor e número de idosos no domicílio são muito semelhantes entre os critérios 1 e 2 , tanto para empregados quanto para empresários. Já o uso do critério 3 sugere que as mulheres têm uma probabilidade ainda maior de serem informais do que quando são usados os dois primeiros critérios. O efeito da educação, que atua no sentido de diminuir a probabilidade de ser informal, mostra-se menos importante para os empresários quando é usado esse critério baseado na ocupação. Para os empregados, a dummy para negros deixa de ser significativa quando o critério 3 é utilizado, sendo positiva em todos os casos para os empresários, assim como pelos dois primeiros critérios entre os empregados.

Os resultados estimados para as dummies de setor de atividade e região geográfica se mostram relativamente mais sensíveis ao critério de classificação para os empresários do que para os empregados. Os efeitos estimados de acordo com o critério de contribuição a previdência para os empresários destoam dos estimados de acordo com os demais critérios em quase todos os setores e regiões. No caso das estimações para setor de atividade há inclusive mudança de sinal nos efeitos para serviços prestados a pessoas, serviços prestados as empresas e indústria, que são positivos no critério 2 e negativos nos demais critérios. No caso das estimações para as regiões também há troca de sinal para a região Centro-Oeste, além de expressiva diferença de magnitude para as regiões Norte e Nordeste.

De acordo com os resultados apresentados na tabela 7, portanto, os efeitos estimados das características do trabalhador, assim como do setor de atividade em que atua, sobre a probabilidade de ser informal dependem fortemente do critério utilizado. Entre os empresários, por exemplo, o fato de residir no Nordeste tem impactos estimados que variam em mais de 10 p.p. dependendo da classificação de informalidade. Diferenças da mesma magnitude são encontradas para o efeito associado ao setor industrial. 


\section{A sensibilidade da análise entre informalidade e bem-estar}

\subsection{Rendimento médio e desigualdade}

A relação entre informalidade e bem-estar passa pela diferença na renda auferida pelos trabalhadores informais em relação aos seus pares que ocupam postos de trabalho formais. A Tabela 8 mostra estatísticas referentes tanto à média quanto à desigualdade nas distribuições do rendimento do trabalho principal dos empregados formais e informais, definidos de acordo com cada um dos critérios de classificação.

Tabela 8

\begin{tabular}{lccccccc}
\hline & \multicolumn{3}{c}{ Formal } & \multicolumn{3}{c}{ Informal } \\
Empregados & carteira & previdência & tamanho & carteira & previdência & tamanho \\
\hline Gini & 0,4267 & 0,4284 & 0,4395 & 0,4584 & 0,4422 & 0,4326 \\
Theil & 0,3866 & 0,3892 & 0,4173 & 0,5097 & 0,4994 & 0,3973 \\
Média do rendimento do trab. principal $^{*}$ & $1.259,12$ & $1.243,30$ & $1.272,90$ & 604,7 & 530,87 & 679,27 \\
\hline
\end{tabular}

* Em R\$ de 2009.

Fonte: PNAD 2009 e 2011.

No que diz respeito à média dos rendimentos do trabalho principal, vale notar que os valores variam mais entre os critérios para o setor informal do que para o formal. Enquanto os valores ficam entre $\mathrm{R} \$$ $1.243,30$ e $\mathrm{R} \$ 1.272,90$ no formal, no setor informal o rendimento varia entre $R \$ 530,87$ e $R \$ 679,27$. Em ambos os casos, o maior valor é registrado para o critério 3 e o menor para o critério 2. Quanto à desigualdade desses rendimentos, os valores também tendem a ser mais sensíveis aos critérios para o setor informal do que para o setor formal. Em ambos os setores, a sensibilidade é maior quando a desigualdade é medida pelo índice de Theil do que pelo índice de Gini. Por exemplo, no setor informal o Theil varia de 0,510 no critério 1 para 0,397 no critério 3. O Gini, que atribui mais peso ao centro da distribuição, é bastante estável entre os diferentes critérios.

A Tabela 9 traz uma análise análoga para os empresários. Para esse grupo, a média dos rendimentos varia sensivelmente com o critério de classificação, tanto para o setor formal como para o informal. Em ambos os setores, os valores computados para os rendimentos pelo critério 3 tendem a ser significativamente maiores que aqueles calculados pelos demais critérios. No que diz respeito aos índices de 
desigualdade computados para o rendimento dos empresários, tanto o índice de Gini como o de Theil mostram variações similares entre os critérios para ambos os setores. Por exemplo, o índice de Theil varia entre 0,520 e 0,614 no setor formal e entre 0,536 e 0,627 no informal. Assim como registrado para os empregados, a sensibilidade da desigualdade do rendimento do trabalho principal é maior com o Theil do que com o Gini.

Tabela 9

\begin{tabular}{lllllll}
\hline & \multicolumn{3}{c}{ Formal } & \multicolumn{3}{c}{ Informal } \\
Empresários & CNPJ & previdência & tamanho & CNPJ & previdência & tamanho \\
\hline Gini & 0,5114 & 0,518 & 0,5564 & 0,5222 & 0,5466 & 0,5475 \\
Theil & 0,5198 & 0,522 & 0,6144 & 0,5363 & 0,6272 & 0,5827 \\
Média do rendimento do trab. principal & $2.891,49$ & $2.575,39$ & $3.762,80$ & 819,01 & 862,95 & $1.052,95$ \\
\hline
\end{tabular}

Fonte: PNAD 2009 e 2011.

A discussão na literatura sobre informalidade e distribuição de renda passa pelo diferencial de salário formal-informal, em particular pela contribuição desse diferencial para a desigualdade de renda. O quanto varia o diferencial de renda formal versus informal vis-àvis a dispersão da renda dentro de cada setor pode ser computado pela decomposição do índice de Theil. Nessa decomposição, ilustrada na Tabela 10, as diferenças entre as distribuições dos rendimentos entre os setores formal e informal são sintetizadas por dois componentes. $\mathrm{O}$ componente intra refere-se às diferenças no grau de desigualdade dentro de cada um dos setores (formal ou informal). Já o componente entre refere-se à diferença nas médias em cada um desses setores.

Tabela 10

\begin{tabular}{|c|c|c|c|c|c|c|}
\hline & \multicolumn{3}{|c|}{ Empregados } & \multicolumn{3}{|c|}{ Empresários } \\
\hline & carteira & previdência & tamanho & CNPJ & previdência & tamanho \\
\hline Theil & 0,4445 & 0,4445 & 0,4445 & 0,717 & 0,717 & 0,717 \\
\hline Desig. entre grupos & 0,0366 & 0,0412 & 0,0318 & 0,1892 & 0,1431 & 0,1258 \\
\hline Desig. intra-grupos & 0,4079 & 0,4033 & 0,4127 & 0,5278 & 0,5739 & 0,5911 \\
\hline \multicolumn{7}{|c|}{ Efeito marginal da informalidade sobre o logaritmo do salário } \\
\hline \multirow{2}{*}{ informal $(A)$} & $-0.761^{\star \star \star}$ & $-0.849^{* \star *}$ & $-0.600^{\star * *}$ & $-1.320^{\star * *}$ & $-1.194^{\star \star *}$ & $-1.218^{\star * *}$ \\
\hline & $(0.00409)$ & $(0.00430)$ & $(0.00383)$ & $(0.00909)$ & $(0.00880)$ & $(0.0162)$ \\
\hline \multirow{2}{*}{ informal (B) } & $-0.376^{\star * \star}$ & $-0.416^{\star * *}$ & $-0.284^{\star \star *}$ & $-0.742^{* * *}$ & $-0.596^{\star * *}$ & $-0.535^{\star \star *}$ \\
\hline & $(0.00341)$ & $(0.00365)$ & $(0.00317)$ & $(0.00897)$ & $(0.00832)$ & $(0.0142)$ \\
\hline
\end{tabular}

(A) Sem controles

(B) Controles: escolaridade, idade, idade ${ }^{2}$, mulher, negro, dummies de região, dummies de setor, dummy de ano, número de idosos no domicílio, número de crianças no domicílio.

Fonte: PNAD 2009 e 2011. 
As três primeiras colunas da Tabela 10 trazem essas decomposições para os empregados, enquanto as três últimas colunas mostram os resultados para os empresários. Os valores expressos nas três primeiras linhas dessa tabela apontam que a sensibilidade na decomposição é muito maior para empresários do que para empregados. Para um Theil de 0,717 para a desigualdade entre empresários agregando ambos os setores, o componente entre varia de 0,126 a 0,189 dependendo do critério de classificação.

Por fim, as duas últimas linhas da Tabela 10 trazem uma estatística que procura contribuir para checar o quanto essa sensibilidade é derivada da distribuição dos indivíduos entre formais e informais. O valor reportado nessa linha é o coeficiente de uma dummy de informalidade $(I)$ em uma regressão do $\log$ dos salários $(\ln (\mathrm{sal}))$ que traz também como controles, no caso da última linha, diversas características individuais e do domicílio $(X)$ :

$$
\ln (\text { sal })=\beta_{0}+\beta_{1} I+\beta_{2} X+\varepsilon
$$

Os resultados mostram que a sensibilidade ao critério de classificação é similar entre os empregados e os empresários. Pode-se destacar, também, que em ambos os grupos de trabalhadores a sensibilidade ao critério de classificação não é afetada de forma significativa pela inclusão de controles na regressão. Por fim, a relação entre rendimentos do trabalho e informalidade é sempre negativa, sendo de maior magnitude no caso dos empresários. O maior efeito para empregados ocorre no critério de contribuição à previdência social e para empresários no critério de inscrição no CNPJ, que são exatamente os casos que registram os maiores valores para a desigualdade entre grupos.

\subsection{Pobreza}

Um indicador de bem-estar de mais apelo para os formuladores de política é o grau de pobreza. É, portanto, relevante saber em que medida a relação entre informalidade e pobreza depende do critério de classificação dos trabalhadores nos setores formal e informal. Para analisar a incidência de pobreza para trabalhadores for- 
mais e informais, é utilizada a linha sugerida pelo Ministério do Desenvolvimento Social e Combate à Fome (MDS), cujo último reajuste foi feito em julho de 2009 pelo Decreto $\mathrm{n}^{\mathrm{O}}$ 6.917. Desta forma, a linha de pobreza é definida como uma renda domiciliar per capita igual a R\$ 140,00. Como foi utilizada a mesma linha para 2009 e 2011, os valores em 2011 são representados em termos de reais de 2009, com base no Índice Nacional de Preços ao Consumidor (INPC).

A Tabela 11 apresenta as proporções de pobres entre grupos de trabalhadores formais e informais para cada um dos critérios. Os resultados são apresentados separadamente para empregados e empresários.

Tabela 11 - Grau de pobreza

\begin{tabular}{lccccccc}
\hline Proporção de pobres (\%) & \multicolumn{2}{c}{$\begin{array}{c}\text { carteira de } \\
\text { trabalho/CNPJ }\end{array}$} & \multicolumn{2}{c}{ previdência } & \multicolumn{2}{c}{ tamanho do estab. } \\
\hline & Informal & Formal & Informal & Formal & Informal & Formal \\
\hline Empregados & 9,3 & 1,6 & 10,5 & 1,7 & 7,3 & 2 \\
Empresários & 11,6 & 0,8 & 11,7 & 1,5 & 9,9 & 1,2 \\
\hline
\end{tabular}

Fonte: PNAD 2009 e 2011.

As proporções de empregados pobres no setor formal variam entre $1,6 \%$ pelo critério da carteira de trabalho e 2,0\% de acordo com o que usa o tamanho do estabelecimento. Para os empregados informais, a incidência de pobreza varia de forma mais intensa, entre 7,3\% pelo critério de tamanho do estabelecimento e 10,5\% no critério baseado na contribuição à previdência social. Já entre os empresários, a incidência da pobreza varia no setor informal entre 9,9\% e 11,7\%, e no setor formal entre $0,8 \%$ e $1,5 \%$. Enquanto no setor informal a menor incidência de pobreza entre empresários ocorre no critério de tamanho, no setor formal ocorre no critério de inscrição no CNPJ.

A sensibilidade da relação entre pobreza e informalidade pode ser vista na Tabela 12. A relação foi estimada por meio de um modelo para a probabilidade de ser pobre, semelhante ao descrito na Expressão (1):

$$
P(R=1 \mid X)=F\left(\beta_{0}+\beta_{1} X\right)
$$


Tabela 12 - Efeito marginal da informalidade sobre a probabilidade de ser pobre, segundo cada critério de informalidade

\begin{tabular}{|c|c|c|c|c|c|c|}
\hline & \multicolumn{3}{|c|}{ Empregados } & \multicolumn{3}{|c|}{ Empresários } \\
\hline & carteira & previdência & tamanho & CNPJ & previdência & tamanho \\
\hline \multirow[t]{2}{*}{$\left.\right|_{\text {nformal }} ^{a}$} & $0.078^{* * *}$ & $0.088^{\star \star *}$ & $0.054^{\star * *}$ & $0.109^{\star * \star}$ & $0.102^{\star \star \star *}$ & $0.087^{\star \star \star}$ \\
\hline & $(0.00120)$ & $(0.00136)$ & $(0.00103)$ & $(0.00144)$ & $(0.00156)$ & $(0.00169)$ \\
\hline \multirow[t]{2}{*}{ Informal $^{b}$} & $0.024^{* \star *}$ & $0.028^{* \star *}$ & $0.016^{* * *}$ & $0.031^{\star \star *}$ & $0.026^{\star \star *}$ & $0.018^{* * *}$ \\
\hline & $(0.00076)$ & $(0.00088)$ & $(0.00061)$ & $(0.00119)$ & $(0.00120)$ & $(0.00191)$ \\
\hline Observações & 230491 & 230491 & 230491 & 90439 & 90439 & 90439 \\
\hline
\end{tabular}

Nota: ${ }^{* *} \mathrm{p}<0.01,{ }^{* *} \mathrm{p}<0.05,{ }^{*} \mathrm{p}<0.1$.

a) Sem controles

b) Controles: escolaridade, idade, idade ${ }^{2}$, mulher, negro, dummies de região, dummies de setor, dummy de ano, número de idosos no domicílio, número de crianças no domicílio.

Fonte: PNAD 2009 e 2011.

A Tabela 12 traz o efeito marginal de ser informal sobre a probabilidade de ser pobre de acordo com duas especificações do modelo. A primeira especificação traz como variável explicativa apenas uma variável indicadora (dummy) do setor do indivíduo (informal $=1$ ). Nessa especificação, ser informal está associado a um aumento entre 5,4 p.p. e 8,8 p.p. na probabilidade de ser pobre para os empregados, e entre 8,7 p.p. e 10,9 p.p. para os empresários. Condizente com os resultados comentados anteriormente, os menores valores são registrados para o critério 3 , tanto para empregados como para empresários.

Já a segunda especificação adiciona como variáveis de controle algumas características do indivíduo que podem estar relacionadas tanto com a sua alocação setorial como com o seu status de pobreza. Nessa especificação, ser informal está associado a um aumento entre 1,6 p.p. e 2,8 p.p. na probabilidade de ser pobre para os empregados, e entre 1,8 p.p. e 3,1 p.p. para os empresários. Novamente, os menores valores são registrados para o critério 3 .

Nas regressões sem controles da Tabela 12, a relação entre o coeficiente estimado para a relação entre informalidade e pobreza varia o correspondente a 3 p.p. para os empregados e o equivalente a 2 p.p. para os empresários. Adicionando os controles, os efeitos passam a 
variar 1,2 p.p. e 1,3 p.p., que representam diferenças de até $80 \%$ em relação aos efeitos estimados pelo critério 3. A incidência de pobreza entre trabalhadores formais e informais, portanto, também se mostra sensível ao critério utilizado para definir informalidade.

\section{Conclusão}

Neste trabalho procurou-se analisar três diferentes critérios para definição de trabalho informal. Usando dados das PNADs 2009 e 2011, compararam-se as características dos trabalhadores formais e informais definidos segundo cada um desses critérios. Essas comparações são realizadas separadamente para empregados e empresários.

De acordo com os resultados, as características dos trabalhadores formais e informais são bastante sensíveis ao critério utilizado para definir informalidade. Da mesma maneira, os diferenciais de rendimentos entre esses dois grupos, assim como a incidência de pobreza para os indivíduos no setor informal, também, costumam variar de acordo com o critério. O próprio tamanho do setor informal depende do critério usado. Em 2009, por exemplo, 27\% dos empregados e $76 \%$ dos empresários seriam classificados como informais pelo critério de contribuição para a previdência. Já pelo critério baseado no tamanho ou na ocupação, essas porcentagens seriam iguais a $36 \%$ e $91 \%$, respectivamente.

O critério fundamentado na inscrição no CNPJ ou na posse da carteira de trabalho geralmente apresenta resultados parecidos com a definição que utiliza a contribuição para a previdência. Isso pode ser observado para as características dos indivíduos que compõem cada um desses grupos, para os diferenciais de rendimentos e para as medidas de distribuição de rendimentos dentro de cada grupo de trabalhadores definidos como formais ou informais. As proporções de pobres entre trabalhadores formais e informais também são semelhantes de acordo com esses dois critérios.

A definição de informalidade, que usa a ocupação ou o tamanho do estabelecimento, no entanto, leva a uma caracterização bem diferente dos indivíduos que atuam no setor informal, e das disparidades nas medidas de bem-estar entre trabalhadores formais e informais. 
No caso dos empresários, esse critério tende a apresentar diferenciais de rendimentos menores entre formais e informais do que os outros dois critérios, assim como uma menor incidência de pobreza.

Os resultados mostrados neste artigo reforçam, portanto, que discussões de políticas voltadas para o setor informal devem ter seus objetivos bastante alinhados com o critério utilizado na definição de informalidade. Diferenças na maneira de definir informalidade podem levar a diagnósticos bem distintos sobre as características dos trabalhadores formais e informais, assim como a diferentes avaliações em termos de bem-estar de cada um desses grupos.

\section{Referências}

BARROS, R. P.; MELLO, R.; PERO, V. Informal contracts: a solution or a problem? Ipea, (Texto para Discussão, n. 291), 1993.

BRASIL. Presidência da República. Decreto n.6917 de 30 de julho de 2009. Disponível em: http://www. planalto.gov.br/ccivil_03/_Ato2007-2010/2009/Decreto/D6917.htm. Acesso em: 19/08/2013.

CACCIAMALI, M. C. (1983) Setor Informal Urbano e Formas de Participação na produção. São Paulo: Ed. IPE, série ensaios econômicos.

CACCIAMALI, M. C. (Pré) conceito sobre setor informal, reflexões parciais embora instigantes. Econômica, v. 9, p. 145-168, 2007.

HALLAK NETO, J.; NAMIR, K.; KOZOVITS, L. Setor e emprego informal no Brasil: análise dos resultados da nova série do sistema de contas nacionais - 2000/07. Economia e Sociedade, v. 21, n.1, p 93-113, 2012.

HENLEY, A.; ARABSHEIBANI, G; CARNEIRO, F. G. On defining and measuring the informal sector: evidence from Brazil. World development, v. 37, n. 5, 2008.

HUSSMANNS, R. Measuring the informal economy: from employment in the formal sector to informal employment. ILO (Working Paper, n. 53), 2004.

KHAMIS, M. A note on informality in the labour market. Journal of international development, v. 24, n. 7, 2012.

KREIN, D. e PRONI, M. Economia Informal: Aspectos conceituais e teóricos. Documento de Trabalho n. 4 da série Trabalho Decente no Brasil: OIT, 2010.

OIT - ORGANIZAÇÃO INTERNACIONAL DO TRABALHO. Employment, income and equality: a strategy for increasing employment in Kenya. Genebra: OIT, 600 p., 1972.

OIT - ORGANIZAÇÃO INTERNACIONAL DO TRABALHO. Decent Work and the Informal Economy. Genebra, 2002.

OIT - ORGANIZAÇÃO INTERNACIONAL DO TRABALHO. Measuring informality: A statistical manual on the informal sector and informal employment. Genebra: 340 p., 2013.

PREALC. Sector informal: funcionamento y politicas. Santiago, Chile, 1978.

RAMOS, C. A. Setor informal: do excedente estrutural à escolha individual. Marcos interpretativos e alternativas de política. Econômica, v. 9, p. 115-137, 2007.

Estud. Econ., São Paulo, vol.45, n.1, p. 5-31, jan.-mar. 2015 
ROCHA, S. Economia Informal: Algumas considerações sobre conceituação e mensuração. IPEA, Texto para Discussão Interna n. 181, 1989.

SCHNEIDER, F.; ENSTE, D. H. Shadow Economies: size, causes, and consequences. Journal of Economic Literature, vol. XXXVIII, pp.77-114, March 2000.

SCHNEIDER, F. The Shadow Economy and Shadow Economy Labor Force: What Do We (Not) Know? IZA Discussion Paper, n. 5769, June 2011.

SOUZA, P. R. O problema ocupacional: o setor informal urbano. In: SERRA, J. Ensaios de interpretação econômica. Rio de Janeiro: Paz e Terra, 1979.

\section{Bibliografia Complementar}

MENEZES-FILHO, N.; MENDES, M.; ALMEIDA, S. O diferencial de salários formal-informal no Brasil: segmentação ou viés de seleção? Revista brasileira de economia, v. 58, n. 2, 2004. 